\title{
REVIEW PAPER
}

\section{Non-clinical interventions that increase the uptake and success of vaginal birth after caesarean section: a systematic review}

\author{
Christine Catling-Paull, Rebecca Johnston, Clare Ryan, Maralyn J. Foureur \& Caroline S.E. Homer
}

Accepted for publication 8 February 2011

Correspondence to C. Catling-Paull: e-mail: christine.catling-paull@uts.edu.au

Christine Catling-Paull MSc RN RM

Research Assistant

Centre for Midwifery, Child and Family Health, Faculty of Nursing, Midwifery and Health, University of Technology Sydney, New South Wales, Australia

Rebecca Johnston RN

Research Officer

Centre for Midwifery, Child and Family

Health, Faculty of Nursing, Midwifery and

Health, University of Technology, Sydney,

New South Wales, Australia

Clare Ryan MSc RM (BMid)

Research Assistant

Centre for Midwifery, Child and Family

Health, Faculty of Nursing, Midwifery and

Health, University of Technology Sydney,

New South Wales, Australia

Maralyn J. Foureur PhD RM

Professor of Midwifery

Centre for Midwifery, Child and Family Health, Faculty of Nursing, Midwifery and Health, University of Technology Sydney,

New South Wales, Australia

Caroline S.E. Homer PhD RM

Professor and Director of Midwifery

Centre for Midwifery, Child and Family Health, Faculty of Nursing, Midwifery and Health, University of Technology Sydney, New South Wales, Australia
CATLING-PAULL C., JOHNSTON R., RYAN C., FOUREUR M.J. \& HOMER C.S.E. (2011) Non-clinical interventions that increase the uptake and success of vaginal birth after caesarean section: a systematic review. Journal of Advanced Nursing 67(8), 1662-1676. doi: 10.1111/j.1365-2648.2011.05662.x

\section{Abstract}

Aim. The aim of this study was to review non-clinical interventions that increase the uptake and/or the success rates of vaginal birth after caesarean section.

Background. Increases in rates of caesarean section are largely due to repeat caesarean section in a subsequent pregnancy. Concerns about vaginal birth after caesarean section have centred on the risk of uterine rupture. Nonetheless, efforts to increase the vaginal birth rate in these women have been made. This study reviews these in relation to non-clinical interventions.

Data sources. Literature was searched up until December 2008 from five databases and a number of relevant professional websites.

Review methods. A systematic review of quantitative studies that evaluated a nonclinical intervention for increasing the uptake and/or the success of vaginal birth after caesarean section was undertaken. Only study designs that involved a comparison group were included. Further exclusions were imposed for quality using the Critical Skills Appraisal Programme.

Results. National guidelines influence vaginal birth after caesarean section rates, but a greater effect is seen when institutions develop local guidelines, adopt a conservative approach to caesarean section, use opinion leaders, give individualized information to women, and give feedback to obstetricians about mode of birth rates. Individual clinician characteristics may impact on the number of women choosing and succeeding in vaginal birth after caesarean section. There is inconsistent evidence that having private health insurance may be a barrier to the uptake and success of vaginal birth after caesarean section.

Conclusion. Non-clinical factors can have a significant impact on vaginal birth after caesarean section uptake and success.

Keywords: caesarean section, hospitals, intervention studies, literature review, maternity, midwifery, systematic review, vaginal birth after caesarean section 


\section{Introduction}

Caesarean rates have increased around the world in the past two decades (Lumbiganon et al. 2010). Most of the increase in rates of caesarean section (CS) is due to repeat CS in a subsequent pregnancy (Thomas et al., 2001; Guise et al. 2003). The UK National Sentinel Caesarean Section Audit reported a mean vaginal birth after caesarean (VBAC) rate of $33 \%$, with a range between units of $6-64 \%$ (Thomas et al., 2001). In Australia in 2006, only $16 \cdot 6 \%$ of women with a history of caesarean section gave birth vaginally (Laws \& Hilder 2008). The reasons are not well researched but may include: fear of uterine rupture in a subsequent labour and birth; fear on the part of healthcare providers who do not offer any choice other than a repeat CS; and convenience for women and clinicians. There are also wide variations in practice guidelines (Foureur et al. 2010). An Australian study showed how discourses with women, positioned caesarean section as a preferential means of birth and as the safe and ordered option (Bryant et al. 2007).

There is no doubt obstetricians' fear of litigation and/or desire for convenience also contributes to rising rates of CS (Hopkins 2000). Other studies have suggested that maternal preference is a factor driving increasing rates of caesarean (Kerr-Wilson 2001) because women fear the pain of vaginal birth (Weaver et al. 2007), have concerns about postpartum sexual function (Lin \& Xirasagar 2005) and the safety of the baby (Villar et al. 2007). A range of personal and societal reasons, including fear of birth and perceived inequality and inadequacy of care, underpins requests for repeat CS (Mccourt et al. 2007). The evidence for large proportions of women requesting CS in the absence of clinical indications has been shown to be weak in a recent study (Weaver et al. 2007). Psychological issues and maternal perceptions of risk were found to be significant factors in many maternal requests.

Caesarean section is not without risk to the woman and the infant in both the short and long term (Morrison et al. 1995, Macdorman \& Singh 1998, Smith et al. 2004, Villar et al. 2006, Richter et al. 2007). There is also evidence that indicates women who give birth to their infants by caesarean section have more negative perceptions of their birth experience, themselves and their infants, exhibit poorer parenting behaviours and may be at higher risk for postpartum mood disturbance compared to women delivering their infants vaginally (Lobel \& Deluca 2007). Therefore it is important to articulate those risks so that women can make an informed choice about a repeat caesarean section or attempt a vaginal birth in a subsequent pregnancy. Articulation of risk in a form that is useful to women and their care providers has not been successfully undertaken to date although recent Austra(c) 2011 The Authors Journal of Advanced Nursing (c 2011 Blackwell Publishing Ltd lian research has provided an insight into the different levels of risk in relation to vaginal birth over CS accepted by women and clinicians (doctors and midwives) (Shorten et al. 2005).

There is evidence that successful vaginal birth after a caesarean section has a probability of $73 \%$ (Landon et al. 2004) or greater and that trial of labour is more cost-effective and provides a higher quality of life (Traynor \& Peaceman 1998, Guise et al. 2003). It is offered as a choice in many settings. Research that endeavours to understand the many factors that impact women's and healthcare provider choices and to understand which models of care or interventions provide the best chance of VBAC success is critical.

A number of evidence-based interventions have been shown to be effective in increasing women's knowledge about birth choices, increasing VBAC, and/or reducing CS rates (Shorten et al. 2005, Chaillet \& Dumont 2007). These have been implemented sporadically, but for the most part, have not been widely disseminated into practice. No overall package of care has been created with the aim of increasing the rate of normal birth, and particularly VBAC.

Both clinical and non-clinical interventions are important regarding the uptake and/or success of VBAC. Clinical interventions involve practices directly affecting women before or during pregnancy or labour (e.g. induction of labour methods, epidural use, X-ray pelvimetry), and nonclinical interventions are those that influence VBAC in a more system-led way (e.g. use of practice guidelines, information for women and clinician characteristics). The distinction between non-clinical and clinical interventions is important as they both require different approaches from a range of disciplines to change practice and improve VBAC rates.

This paper reviews randomized trials and non-randomized studies that evaluated any non-clinical intervention designed to either increase the proportion of women choosing a VBAC or increase the VBAC success rate. This was undertaken to identify which interventions could be tested together in an overall package of care. Clinical interventions which influence the uptake and success of VBAC are reported elsewhere (Catling-Paul et al. 2010).

\section{Method of review}

\section{Aim}

The aim of this review was to identify the most effective ways to increase the rate of VBAC. The focus was on identifying the most effective interventions (before and during pregnancy and during labour) that would increase both the uptake of attempted VBAC and/or the rate of successful VBAC. 


\section{Design}

A systematic review of quantitative studies was carried out using the Cochrane Guidelines for a Systematic Review (Higgins \& Green 2009) with specific adaptations. Due to the scarcity of Randomised Controlled Trials (RCT), a greater range of studies was chosen for inclusion in the review. The Critical Appraisal Skills Programme (CASP) (Public Health Resource Unit, 2007) for quantitative studies was used to critique papers for quality.

\section{Search methods}

The PICO principles (population, intervention, comparison and outcome) were used to formulate clinical questions that guided the search strategy (Richardson et al. 1995). The questions were: What is the uptake and success rates of VBAC (O) for women who have had a previous caesarean section $(\mathrm{P})$ comparing a range of interventions (I) compared with no intervention or different interventions (C). Essentially, we were interested in what makes a difference to the VBAC uptake and success rates.

An unrestricted search of CDSR (Cochrane Database of Systematic Reviews), CINAHL (Cumulative Index to Nursing \& Allied Health), Ovid MEDLINE(R), MIDIRS (Maternity and Infant Care), and PsycINFO was undertaken to determine any studies that evaluated an intervention for VBAC. Government health websites and obstetric and midwifery professional organization websites were searched. Reference lists of relevant articles, including any guidelines and reviews, were also examined. All studies that evaluated an intervention for increasing either the uptake of and/or the success of VBAC were considered for inclusion. Only study designs that involved a comparison group were considered appropriate (randomized controlled trials, cohort studies, case control studies and before and after studies). Studies that did not report VBAC uptake or success rates were excluded. All studies were considered up to December 2008. Systematic reviews were used to source further publications but were not included as part of this review. Only primary sources were considered appropriate for this review.

Keywords used: 'Intervention' and 'Pregnancy Outcome' with 'Vaginal Birth After C(a)esarean/Caesarian', 'VBAC', 'Trial of Labo(u)r', 'C(a)esarean/Caesarian Section', and 'C(a)esarean/Caesarian Section, repeat'.

\section{Quality appraisal}

Studies were rated using the Critical Appraisal Skills Programme (CASP) (Public Health Resource Unit, 2007).
CASP is a specifically developed internationally used programme designed to encourage an evidence-based approach to health and social care. Scores were given related to quality: $<5$ - Poor, 6-9 - Fair, and 10-12 - Good. Studies deemed poor were evaluated by a second reviewer to confirm the rating and thus their exclusion. This resulted in two studies moving from poor to fair. Finally, 31 studies were deemed good, 30 fair and 17 poor. Hence, there were 61 good or fair included studies, 27 covering non-clinical interventions and 34 covering clinical interventions to either increase the uptake and/or success of VBAC (Figure 1). The 27 studies reporting non-clinical interventions are included in this review.

\section{Data abstraction and synthesis}

Three independent reviewers extracted data that described a non-clinical intervention to increase the uptake and/or success of VBAC, and had a comparison group. Papers were then grouped into three major categories and a narrative summary was undertaken. A meta-analysis was not appropriate due to the heterogeneity and lack of studies.

Studies were included that did not report full statistical data on their outcomes. The inclusion of studies with inadequate statistical reporting is recognized as a possible potential for bias, and a weakness of the study. However, given the lack of research in this field, exclusion of these studies would have restricted this review.

\section{Findings}

The search found five RCTs concerning non-clinical interventions for increasing VBAC uptake or success. There were nine retrospective and one prospective cohort studies, one case-control study and eleven before and after studies (Table 1). Characteristics of the studies are summarized in Table 2. The findings are presented in the next section by topic or thematic category. The main headings are Information/guidelines for providers, Context/style of care, and Information for women.

\section{Information/guidelines for providers}

This category examined studies that looked at the effectiveness of information and/or guidelines addressing the practices surrounding VBAC provided to healthcare providers.

Twelve papers were included.

\section{Guidelines}

Nine studies (Kosecoff et al. 1987, Myers \& Gleicher 1988, 1993, Lomas et al. 1989, Iglesias et al. 1991, Santerre 1996, 
Figure 1 A flowchart of excluded and included studies. Non-Clinical interventions = practices indirectly affecting women's VBAC uptake/success (e.g. hospital guidelines). Clinical interventions $=$ practices directly affecting women's VBAC uptake/ success (e.g. induction of labour methods).

Studnicki et al. 1997, Sanchez-Ramos et al. 2000, Blanchette et al. 2001) (all before and after studies) assessed the impact of new guidelines, policies or programmes for CS or VBAC (either local or national) on the uptake, success or overall rate of VBAC. Seven of these (Kosecoff et al. 1987, Myers \& Gleicher 1988, 1993, Iglesias et al. 1991, Santerre 1996, Studnicki et al. 1997, Sanchez-Ramos et al. 2000) reported an increase in VBAC rates to varying degrees.

National guidelines increased the VBAC rate in three studies. Studnicki et al. (1997) reported an increase in VBAC rates from $22 \%$ to $31 \%$ when state legislation was changed to mandate the distribution of practice guidelines about CS to all obstetricians (Florida, USA). Santerre (1996) demonstrated that the distribution of the American College of (C) 2011 The Authors Journal of Advanced Nursing (C) 2011 Blackwell Publishing Ltd
Excluded $(n=>1120)$ were articles did not describe interventions to increase the uptake of VBAC or the increased success of attempted VBAC.
Full text articles selected for potential inclusion $(n=174)$
96 Exclusions:

1. No comparison group $(n=35)$

2. Inapropriate comparison groups $(n=9)$

3. Did not have an intervention to increase VBAC uptake or success $(n=30)$

4. Did not specifically report on VBAC uptake or success $(n=10)$

5. Review papers $(n=12)$

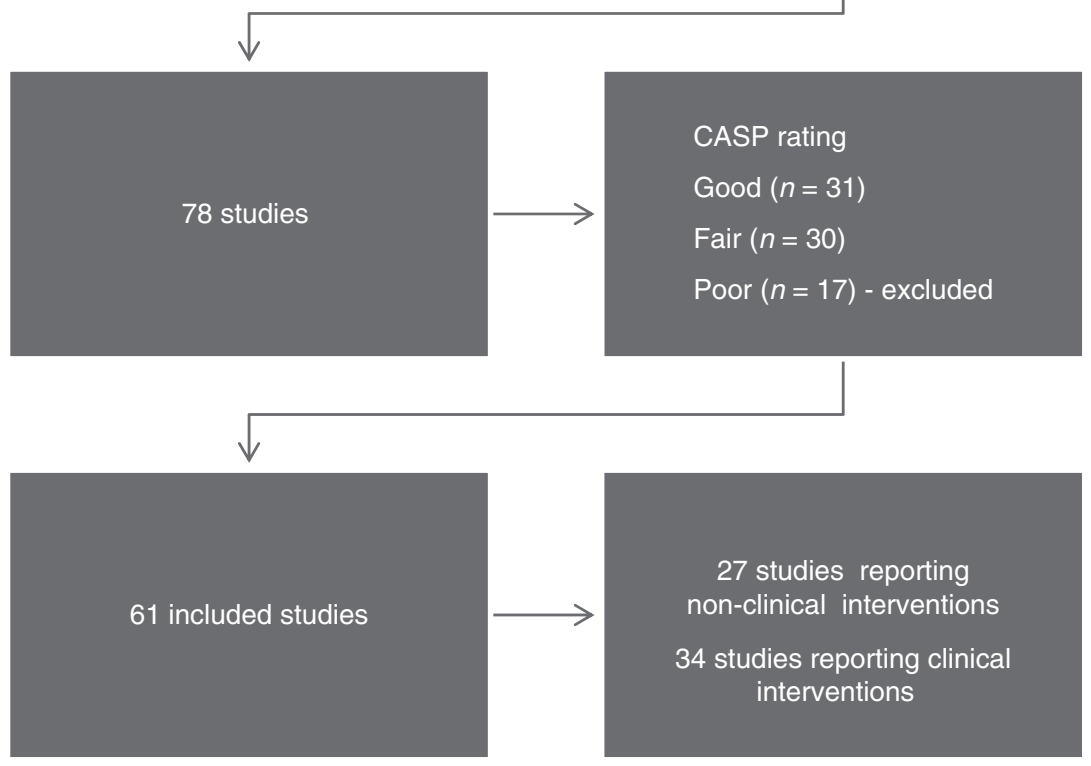

Obstetricians and Gynecologists (ACOG) guidelines on VBAC across 55 hospitals led to an increase in VBAC rates from $12 \cdot 6 \%$ to $18 \cdot 5 \%$. Lomas et al. (1989) when assessing the impact of Canadian national guidelines in 140 hospitals, reported no change in VBAC rates when hospital data were analysed, although the majority of obstetricians and hospitals surveyed claimed a decrease in their use of repeat CS. Kosecoff et al. (1987) analysed the effect of the NIH Consensus Development Program on the VBAC rates in 10 hospitals in the United States of America (USA) and found that VBAC uptake increased from $11 \%$ to $29 \%$ and the overall VBAC rate rose from $6 \%$ to $16 \%$. Iglesias et al. (1991) showed a remarkable increase in VBAC uptake (from $7 \%$ of eligible women to $79 \%$ ) when a small community 


\begin{tabular}{|c|c|c|c|}
\hline Trial (author and date) & Country & Design & CASP rating \\
\hline \multicolumn{4}{|c|}{ Information/guidelines for providers $(n=12)$} \\
\hline Bickell et al. (1996) & USA & Cluster RCT & GOOD \\
\hline Lomas et al. (1991) & Canada & Cluster RCT (3 groups) & GOOD \\
\hline Kosecoff et al. (1987) & USA & Before and after (retrospective) & FAIR \\
\hline Lomas et al. (1989) & Canada & Before and after (prospective) & FAIR \\
\hline Myers \& Gleicher (1988) & USA & Before and after (prospective) & FAIR \\
\hline Myers \& Gleicher (1993) & USA & $\begin{array}{l}\text { More long term outcomes from } \\
1988 \text { study }\end{array}$ & FAIR \\
\hline Iglesias et al. (1991) & Canada & Before and after (retrospective) & GOOD \\
\hline Studnicki et al. (1997) & USA & Before and after (retrospective) & FAIR \\
\hline Santerre (1996) & USA & Before and after (retrospective) & GOOD \\
\hline Blanchette et al. (2001) & USA & Before and after (prospective) & GOOD \\
\hline Naiden \& Deshpande (2001) & USA & Before and after (retrospective) & FAIR \\
\hline Sanchez-Ramos et al. (1990) & USA & Before and after (retrospective) & FAIR \\
\hline \multicolumn{4}{|l|}{ Context/style of care $(n=11)$} \\
\hline Chang et al. (2008) & USA & Retrospective cohort & GOOD \\
\hline Defranco et al. (2007) & USA & Retrospective cohort & GOOD \\
\hline Dunsmoor-Su et al. (2003) & USA & Retrospective cohort & GOOD \\
\hline Lagrew \& Adashek (1998) & USA & Retrospective cohort & FAIR \\
\hline Misra (2008) & USA & $\begin{array}{c}\text { Before and after } \\
\text { (retrospective) }\end{array}$ & FAIR \\
\hline Paterson \& Saunders (1991) & UK & Retrospective cohort & FAIR \\
\hline Russillo et al. (2008) & Canada & Retrospective cohort & GOOD \\
\hline Wagner \& Metts (1999) & USA & Retrospective cohort & FAIR \\
\hline Stafford (1991) & USA & Retrospective cohort & GOOD \\
\hline Hanley et al. (1996) & USA & Retrospective cohort & FAIR \\
\hline Goldman et al. (1993) & Canada & Case-control study & GOOD \\
\hline \multicolumn{4}{|l|}{ Information for women $(n=4)$} \\
\hline Fraser et al. (1997) & Canada & RCT & GOOD \\
\hline Montgomery et al. (2007) & UK & RCT & GOOD \\
\hline Shorten et al. (2005) & Australia & RCT & GOOD \\
\hline Cleary-Goldman et al. (2005) & USA & Prospective cohort & GOOD \\
\hline
\end{tabular}

Table 1 Details and CASP rating of included studies by category area hospital changed its guidelines in line with the National (Canadian) Consensus Conference on Aspects of Caesarean Birth (NCCACB) for vaginal birth after CS.

Three studies examined the influence of local guidelines, two of which showed a beneficial impact on VBAC rates. Sanchez-Ramos et al. (1990) showed a statistically significant improvement in both the uptake of VBAC (32-84\%) and the success of VBAC (65-83\%) when clinicians were encouraged to take a more conservative approach to CS. Myers and Gleicher published two studies demonstrating the short- and long-term impact of a hospital initiative to reduce its CS rate (Myers \& Gleicher 1988, 1993). Following the changes, the uptake of VBAC in the hospital increased from $45 \%$ to $86 \%$, and remained high after 6 years despite the fact that the proportion of women presenting with a repeat CS doubled $(7-14 \%)$. Likewise, the success rates of VBAC improved from $53 \%$ to $70 \%$ and continued to improve to $78 \% 6$ years later.

The only study in this category to report a negative result was Blanchette et al. (2001), who demonstrated that, despite encouraging all obstetricians to promote VBAC more often, there was a $7 \%$ decline in VBAC rates in the 4-year study period. This was consistent with national trends of declining VBAC at the time, and demonstrates that hospital management and policies are not the sole driving forces behind obstetric decision-making.

\section{Audit and feedback}

Three studies (Lomas et al. 1991, Bickell et al. 1996, Naiden \& Deshpande 2001) (two RCTs and one before and after study) assessed the impact of regular audits and feedback to clinicians regarding CS rates. Bickell et al. (1996) in a cluster randomized controlled trial demonstrated no difference between hospitals that underwent the audit process and those that did not, although an overall increase in VBAC rates was observed in all hospitals across the period studied.

Lomas et al. (1991) also conducted a cluster RCT where hospitals were randomly allocated to one of three groups: no intervention $(n=8)$; opinion leader intervention $(n=4)$; or, 


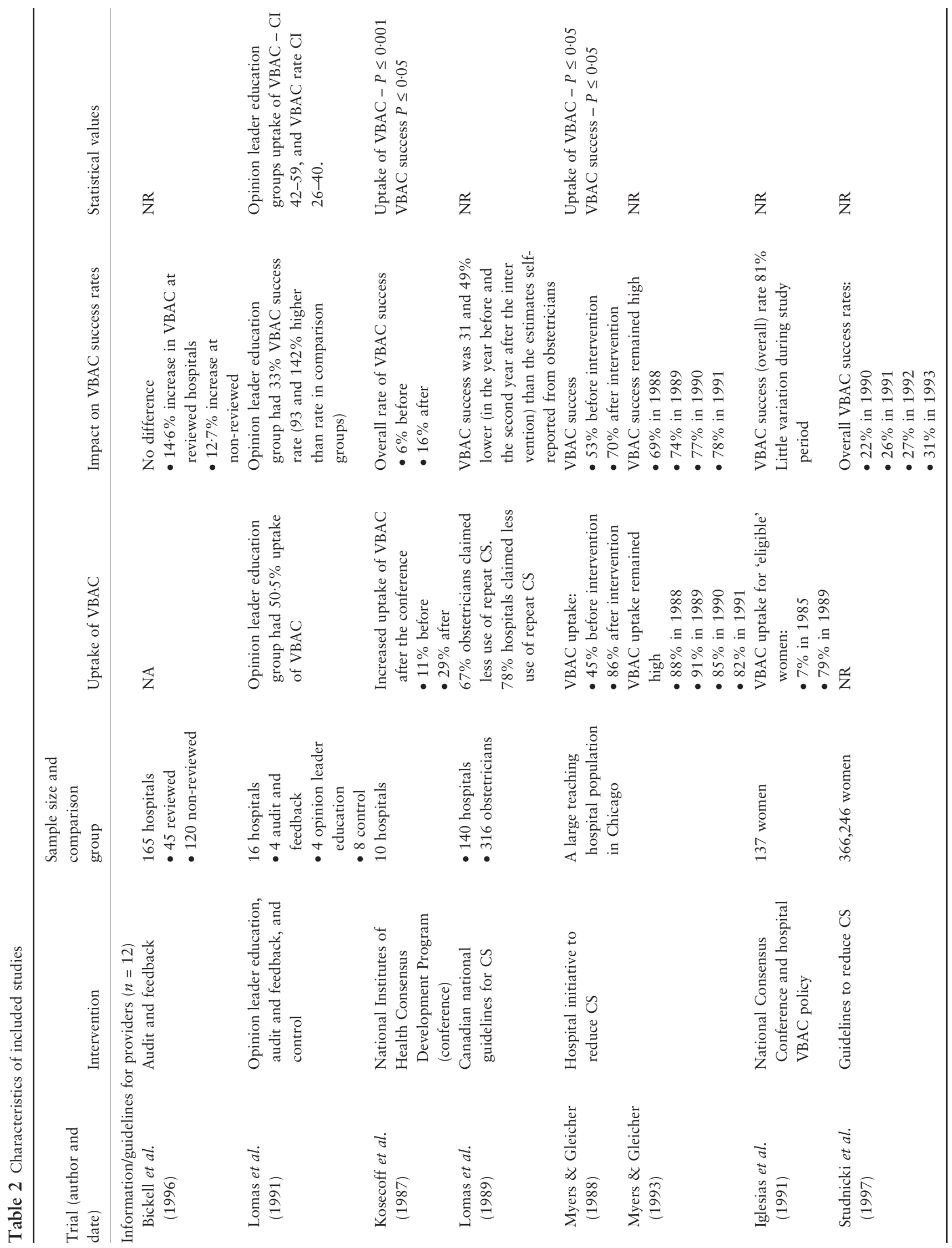

(C) 2011 The Authors 


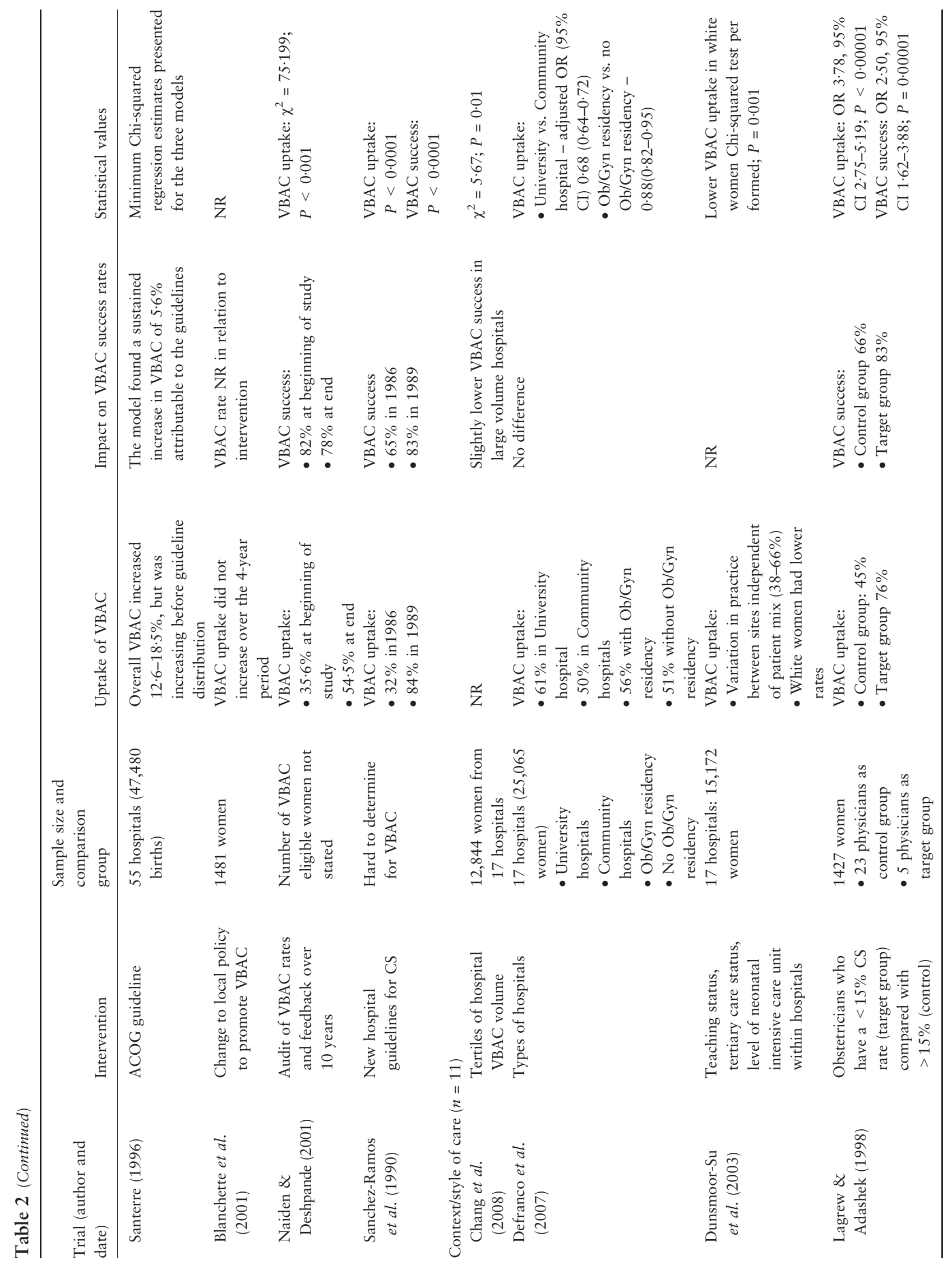

(c) 2011 The Authors Journal of Advanced Nursing (c) 2011 Blackwell Publishing Ltd 


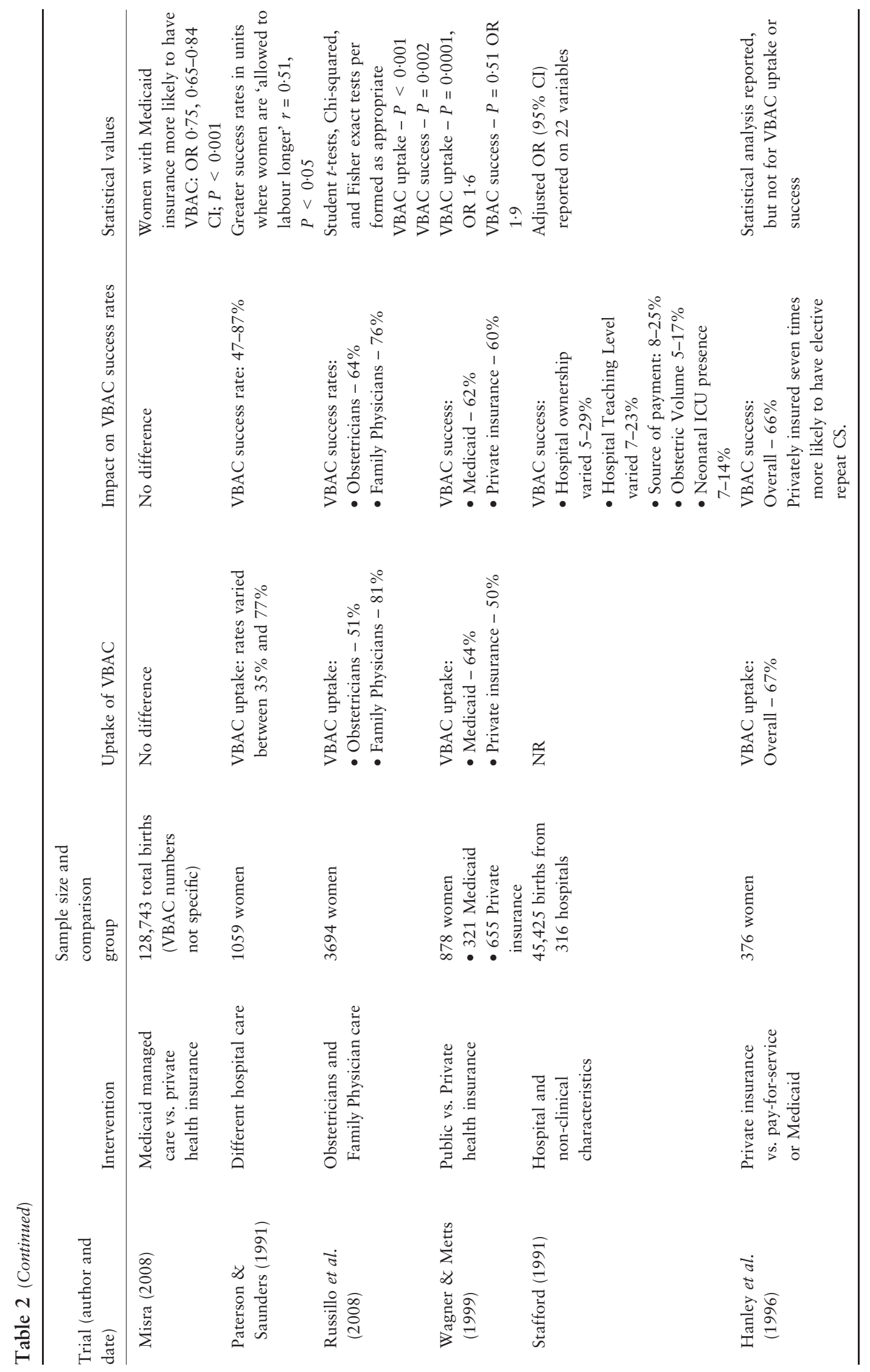

(C) 2011 The Authors 


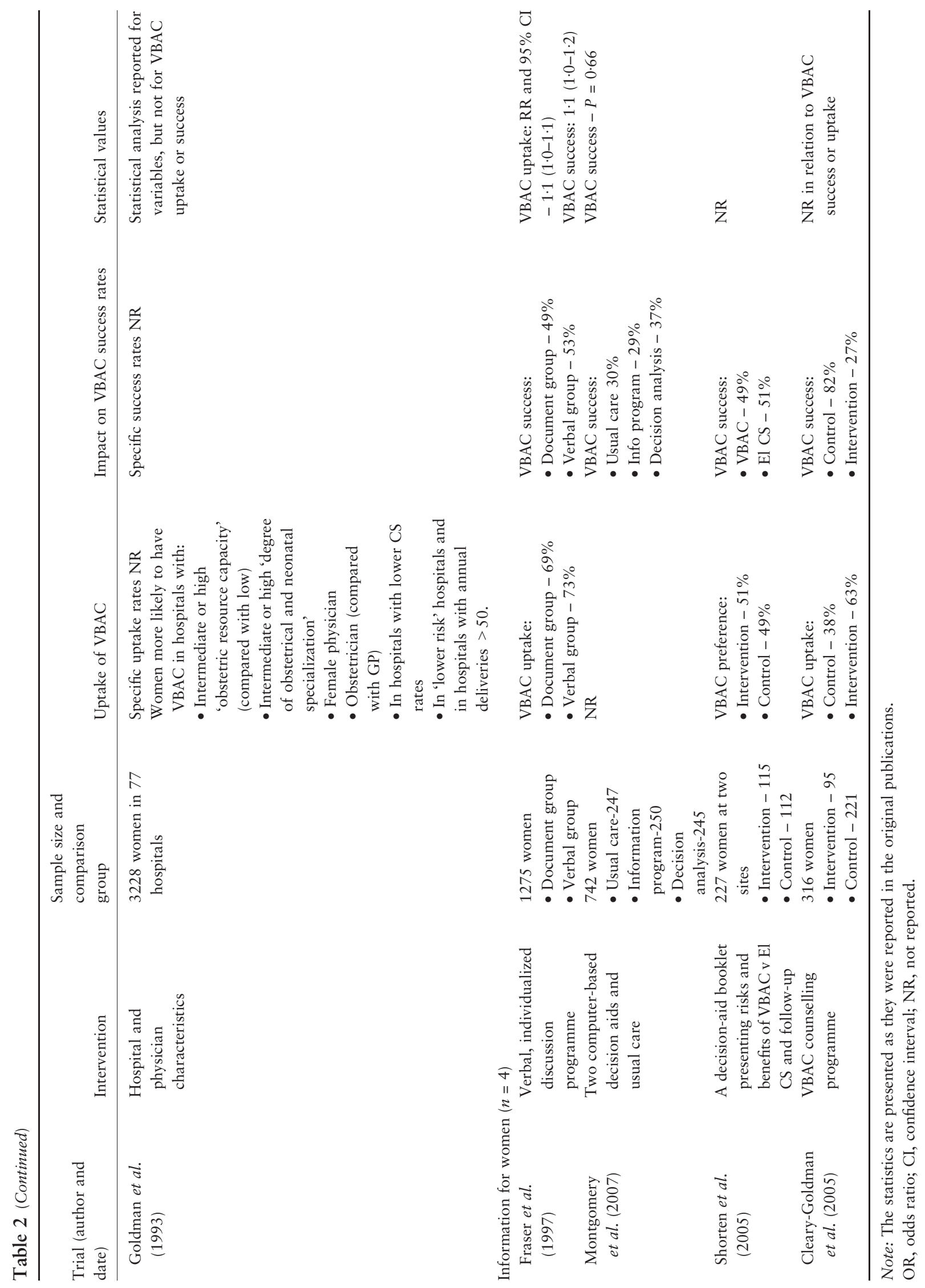


audit and feedback intervention $(n=4)$. The opinion leader intervention included having self-identified physician leaders in the hospitals. These physicians attended a 11/2-day workshop on evidence for the practice guideline on VBAC produced by the Society of Obstetricians and Gynecologists of Canada and ongoing contact over a 12-month period that consisted of regular information on topics that might have been of concern to the opinion leaders and their colleagues, the hosting of a meeting with an expert speaker and encouraging of educational contacts and opportunities. The audit and feedback intervention consisted of having criteria for the indication for CS in women with a prior CS, medical audits of the charts of all women with a previous CS and holding regular meetings of the entire department for feedback and discussion about the audit results and the disparities between the criteria and actual practice. There were statistically significant differences in the rates of women offered a VBAC (opinion leader $74 \%$, audit and feedback $56 \%$, no intervention $51 \%, P=0.002$ ), rates of women attempting a VBAC (opinion leader $38 \%$, audit and feedback $21 \%$, no intervention $28 \%, P=0 \cdot 007$ ), VBAC rates (opinion leader $25 \%$, audit and feedback $12 \%$, no intervention $14 \%$, $P=0.003$ ), and elective CS rate (opinion leader $54 \%$, audit and feedback $70 \%$, no intervention $67 \%, P=0.001)$. There were no statistically significant differences in rates of emergency CSs. While multiple comparisons were not made to determine exactly which groups differed from one another, opinion leaders seem to have a greater impact in increasing both the uptake of VBAC and the VBAC success rates than audit and feedback.

The final study assessing audit and feedback to clinicians was a prospective before and after study by Naiden and Deshpande (2001). Individual obstetricians were audited for the CS rates and those with high rates were often asked to defend their decisions. Over a 10-year period the overall CS rate in the hospital fell from $16 \cdot 6 \%$ to $10 \cdot 9 \%$ of all births and remained low. This was primarily due to a reduction in the repeat CS rate, and an increase in VBAC uptake from $35.6 \%$ to $54.5 \%$. There was no difference in the success rates of women attempting a VBAC in this period, demonstrating that a significant contribution to increasing the overall VBAC rates comes by increasing the uptake.

\section{Context/style of care}

This category examined different hospital (e.g. size, tertiary or non-tertiary) and physician characteristics (e.g. obstetrician or GP), and health insurance status in relation to VBAC uptake and/or success. Eleven studies were included in this category.

(C) 2011 The Authors

Journal of Advanced Nursing (c 2011 Blackwell Publishing Ltd

\section{Hospital and/or physician characteristics}

Eight studies (Paterson \& Saunders 1991, Stafford 1991, Goldman et al. 1993, Lagrew \& Adashek 1998, Dunsmoor-Su et al. 2003, Defranco et al. 2007, Chang et al. 2008, Russillo et al. 2008) (seven cohort and one before and after study) assessed the impact of hospital/clinician characteristics on the attempted and successful VBAC rate. Two studies reported that VBAC was more likely to occur in university/teaching hospitals (Stafford 1991, Defranco et al. 2007), with one study (Dunsmoor-Su et al. 2003) reporting no difference. Chang et al. (2008) reported lower VBAC success rates in large volume hospitals, although they did report on the levels of uptake of VBAC by hospital type. Interestingly, one study (Paterson \& Saunders 1991) reported that, although VBAC uptake varied from hospital to hospital, hospitals which 'allowed women to labour longer' had higher rates of successful VBAC, regardless of uptake.

A large study by Goldman et al. (1993) assessed the hospital and physician characteristic that affected VBAC rates. Women were more likely to have a VBAC in hospitals with intermediate or high 'obstetric resource capacity' (i.e. presence of obstetricians, number of births a year, number of beds), with intermediate or high 'degree of obstetrical and neonatal specialization', with a female physician, with an obstetrician rather than a GP, in hospitals with lower overall CS rates, and in hospitals with more than 50 births per year. Conversely, Russillo et al. (2008) found that women under the care of a family physician were much more likely to attempt a VBAC ( $81 \%$ vs. $51 \%)$ and were more likely to be successful $(76 \%$ vs. $64 \%)$. Similarly, Lagrew and Adashek (1998) found that, in a cohort of women who were under the care of an obstetrician, women were much more likely to attempt ( $76 \%$ vs. $45 \%)$ and achieve ( $83 \%$ vs. $66 \%$ ) VBAC if their obstetrician had an overall CS rate below $15 \%$ compared with those whose overall rate was greater than $15 \%$.

\section{Health insurance status}

Three studies (Hanley et al. 1996, Wagner \& Metts 1999, Misra 2008) examined the effect of health insurance status on women's uptake or success of VBAC. All were retrospective cohort studies and all compared women with private health insurance to women under the public system or the Medicaid system (the USA's health programme for eligible individuals and families with low incomes and resources).

Misra (2008) reported no difference between the groups concerning uptake or success of VBAC. Wagner and Metts (1999), reported that privately insured women were less likely to attempt VBAC (50\% vs. $64 \%)$ with lower success rates. Similarly Stafford (1990) found VBAC rates were 
significantly lower in privately insured women $(8 \cdot 1 \%)$ compared with women using the public system $(25 \%)$. Hanley et al. (1996) reported that privately insured women were seven times more likely to have an elective repeat CS following a previous CS.

Santerre (1996) also reported on the effects of private health insurance and found no differences in the rates of VBAC with privately insured or women in public system. This review was primarily about the effect of guidelines on practice and was placed in the category 'information/guidelines for providers'.

\section{Information for women}

This category addressed the effectiveness of ways to provide information to women about VBAC and elective CS to observe whether VBAC uptake or success was increased.

The impact of the provision of information to women about VBAC was addressed in four studies, three of which were RCTs (Fraser et al. 1997, Shorten et al. 2005, Montgomery et al. 2007). One study was a prospective cohort (Cleary-Goldman et al. 2005).

The first trial was designed to assess whether a prenatal education and support programme promoting vaginal birth after caesarean delivery increased the probability of vaginal birth (Fraser et al. 1997). The trial was conducted in 11 hospitals in Canada and one in the USA. Women were randomized to either a verbal-based (individualized discussion) programme or a document-based (pamphlet) prenatal programme for those attempting a VBAC. Although statistically non-significant, the VBAC rate was higher in the verbal-based programme compared with those in the document-based programme $(53 \%$ and $49 \%$, respectively; RR, $1 \cdot 1 ; 95 \%$ CI, $1 \cdot 0-1 \cdot 2)$.

The second trial was conducted in the United Kingdom (UK). The trial examined the effects of two computer-based decision aids on decisional conflict and mode of birth among 742 women with a previous CS (Montgomery et al. 2007). There were two intervention groups and one control group who had usual care. Both interventions were delivered using a laptop computer after brief instructions from a researcher. The first intervention was an information program that provided descriptions and probabilities of clinical outcomes for mother and baby associated with planned vaginal birth, elective CS, and emergency CS. The second intervention was a decision analysis which recommended a mode of birth based on utility assessments performed by the woman combined with probabilities of clinical outcomes in a concealed decision tree. Women in the intervention groups had reduced decisional conflict compared with women in the usual care group. The rate of VBAC was higher for women in the decision analysis group compared with the usual care group although this was not statistically significant $(37 \%$ and $30 \%$, respectively; Adjusted OR, 1.42; 95\% CI 0.94-2.14).

The third trial was conducted in Australia. Shorten et al. (2005) aimed to determine whether a decision-aid for women who have a previous caesarean facilitated decision-making about birth options in the subsequent pregnancy in a trial of 227 women. Women randomized to the intervention group were given a decision-aid booklet at 28 weeks' gestation describing the risks and benefits of elective repeat CS and trial of labour. The intervention group had a statistically significant reduction in decisional conflict about choice of birth; however, the decision-aid did not significantly affect the rate of uptake of trial of labour or elective repeat CS.

Finally, a prospective cohort study assessed the impact of an antenatal counselling programme on women's choice for VBAC (Cleary-Goldman et al. 2005). There were 316 women in the study, 95 of whom participated in the counselling programme and 221 who acted as the control group. Sixty three percent of women in the counselling programme attempted VBAC compared with only $38 \%$ in the control group. Of those electing a VBAC in the study group, there was a success rate of $59 \%$. Interestingly $82 \%$ of the women electing VBAC in the control group had a successful VBAC.

\section{Discussion}

The studies included in this systematic review cover a 20-year time span. We are mindful that during this time many practices around caring for women having a VBAC have changed. For example, practices have changed considerably around induction of labour in women who have had a previous caesarean. Also data quality and coding has changed over this time period. For example there have been inaccuracies reported with ICD-9 codes (American Medical Association, 1995; Reker et al. 2001), and as such, studies using these codes in their methods may be erroneous. A metaanalysis was not undertaken.

Non-clinical factors can have a significant impact on uptake and success rates of VBAC. Local ownership of the desire to reduce CS rates or increase VBAC rates may be the most influential non-clinical factor in improving uptake and success rates of VBAC. This would explain why studies assessing local hospital policies or guidelines about the management of women with a previous CS showed a greater impact on uptake and/or success rates than studies that assessed the impact of national guidelines for VBAC. The effect of national guidelines is diminished by institutions that choose not to follow them. Furthermore, the attitudes of 


\section{What is already known about this topic}

- A high proportion of the already high caesarean section rate around the world consists of women with a prior caesarean electing to have a repeat caesarean for a subsequent birth.

- Health institutions vary considerably in regard to their acceptance, uptake, support and success of women undergoing a vaginal birth after caesarean.

\section{What this paper adds}

- Non-clinical interventions such as guidelines, audit and feedback and characteristics of clinicians have an impact on vaginal birth after caesarean rates.

- Guideline changes that are implemented at a local level, and therefore perhaps more likely to be owned and driven by the clinicians working in the institution, appear to have a greater effect on practice than guidelines that are developed and distributed on a large scale.

- Providing evidence-based individual information about the issues related to repeat caesarean sections and vaginal birth after caesarean enables women to make easier decisions about mode of birth, and may increase vaginal birth after caesarean attempt and success.

\section{Implications for practice and/or policy}

- Given the potential adverse health risks to both mothers and babies as a result of caesarean sections, further work towards lowering the rate of repeat caesareans is necessary.

- Health organizations should implement evidence-based local guidelines to increase the uptake and success of vaginal birth after caesarean.

- Health organizations should implement vaginal birth after caesarean decisional aids and develop specific clinics in existing antenatal clinics to address the need for clear and consistent, evidence-based informationsharing with women.

individual clinicians can influence VBAC outcomes. Opinion leaders may have a significant effect on VBAC rates in hospitals, and obstetricians with an overall CS rate of less than $15 \%$ are more likely to have higher VBAC rates. Whether or not an audit and feedback policy for obstetricians is of benefit is uncertain. Where there is a personal interest in increasing VBAC rates, feedback processes may be beneficial, but where individual obstetricians do not express a desire to (C) 2011 The Authors Journal of Advanced Nursing (C) 2011 Blackwell Publishing Ltd encourage or support VBAC then audit and feedback may prove to make no difference.

A few studies reported that VBAC was more likely to occur in teaching hospitals or hospitals that had higher levels of obstetric support. This probably represents hospitals that have a high emphasis on evidence-based practice, and those which have more experience in managing VBAC. It may also indicate the fear of many institutions and authorities regarding VBAC in smaller hospitals with less obstetric cover. For example, in 1999, a change in the uptake of VBAC was highly apparent in the USA after ACOG revised their guidelines and advised a more conservative approach towards VBAC. Roberts et al. (2007) reported that over 30\% of services that were previously offering VBAC no longer did so after the change in guidelines. Smaller and more isolated hospitals were more likely to discontinue offering VBAC. Of those that continued to offer VBAC, the majority $(68 \%)$ changed their policies in line with the provision of onsite surgical and anaesthetic staff. Similarly, in California, attempted VBAC fell from $24 \%$ to $13.5 \%$ following release of the new guidelines (Zweifler et al. 2006). International guidelines do not always provide consistent evidence either which complicates matters (Foureur et al. 2010).

Some studies show that private health insurance status negatively affects VBAC rates. This is a complex matter that other studies have shown to be false. Health insurance does not in and of itself impact VBAC rates, but it is likely a marker for other confounding variables such as the use of a private obstetrician, hospital characteristics, higher socioeconomic status, older maternal age, and higher levels of maternal education. In general, Australian women are more likely to have intervention if attended by private obstetricians (Roberts et al. 2000), although this is also controversial (Robson et al. 2009).

Giving women information about their options for mode of birth following a CS is likely to be beneficial. Although the three included RCTs in this category did not show a statistically significant increase in VBAC uptake among women given information or support in pregnancy, two of the three (Frazer et al., 1997; Montgomery et al. 2007) showed trends towards higher VBAC rates in the intervention group. Two (Shorten et al. 2005, Montgomery et al. 2007) also demonstrated a reduction in decisional conflict for women given decision-making tools in pregnancy to assist them in assessing their options. Reducing women's decisional conflict and involving women more fully in decision-making is an important aspect of obstetric and midwifery care. An intervention that reduces decisional conflict and provides women with evidence-based information about the options should be incorporated into the management of all women 
with a previous CS. This could be through more widespread implementation of decisional aids and 'next birth after caesarean' clinics in existing antenatal clinics.

\section{Conclusion}

National and local guidelines can have a significant impact on VBAC rates, particularly by increasing the number of women who attempt VBAC. Guideline changes that are implemented at a local level, and therefore perhaps more likely to be owned and driven by the clinicians working in the institution, appear to have a greater effect on practice than guidelines that are developed and distributed to large scale organizations.

Audit and feedback studies have the potential to make a significant difference in the uptake and success of VBAC. However, opinion leaders are more likely to guide a change of practice.

Hospital and physician characteristics vary markedly and may reflect cultural expectations, fear of liability, confidence and competence in certain skills and levels of importance placed on evidence based care. It is therefore not surprising that studies showed varying results regarding the impact of hospital and physician characteristics on the uptake and success of VBAC.

Women may have a higher uptake of VBAC, and have reduced decisional conflict about their chosen mode of birth when given information individually, especially verbally. Midwives can be pivotal to information delivery. The development of specific clinics to streamline the consistency of information to women who have had previous caesarean section is recommended.

\section{Acknowledgements}

The BACI (Birth after Caesarean Intervention) Consortium.

\section{Funding}

ARACY (Australian Research Alliance for Children and Youth) for startup funding.

\section{Conflict of interest}

Maralyn Foureur and Caroline Homer are both members of the BACI Consortium.

\section{Author contributions}

RJ, CR, MF \& CH were responsible for the study conception and design. RJ, CR \& $\mathrm{CH}$ performed the data collection.
CC-P, RJ, CR \& CH performed the data analysis. CC-P, RJ, $\mathrm{CR} \& \mathrm{CH}$ were responsible for the drafting of the manuscript. CC-P, MF \& $\mathrm{CH}$ made critical revisions to the paper for important intellectual content. MF obtained funding. CC-P, RJ, CR, MF \& $\mathrm{CH}$ provided administrative, technical or material support. MF \& CH supervised the study.

\section{Supporting Information Online}

There is no Supporting Information associated with this article.

\section{References}

American Medical Association (1995) International Classification of Disease, $9^{\text {th }}$ Revision, Clinical Modification, Vol 1. American Medical Association Press, Baltimore, MD.

Bickell N.A., Zdeb M.S., Applegate M.S., Roohan P.J. \& Sui A.L. (1996) Effect of external peer review on cesarean delivery rates: a statewide program. Obstetrics \& Gynecology 87, 664-667.

Blanchette H., Blanchette M., Mccabe J. \& Vincent S. (2001) Is vaginal birth after cesarean safe? Experience at a community hospital American Journal of Obstetrics \& Gynecology 184, 1478-1484. discussion 1484-1487.

Bryant J., Porter M., Tracy S. \& Sullivan E. (2007) Caesarean birth: consumption, safety, order, and good mothering. Social Science and Medicine 65, 1192-1201.

Catling-Paull C., Johnstone R., Ryan C., Foureur M. \& Homer C. (2010) Interventions for increasing the rates of uptake or success of vaginal birth after caesarean section (VBAC). Technical Report. Retrieved from http://www.nmh.uts.edu.au/cmcfh/research/birthafter-caesarean-interventions.html on 14 March 2010.

Chaillet N. \& Dumont A. (2007) Evidence-based strategies for reducing caesarean section rates: a meta analysis. Birth 34(1), 53-64.

Chang J.J., Stamilio D.M. \& Macones G.A. (2008) Effect of hospital volume on maternal outcomes in women with prior cesarean delivery undergoing trial of labor. American Journal of Epidemiology 167, 711-718.

Cleary-Goldman J., Cornelisse K., Simpson L.L. \& Robinson J.N. (2005) Previous cesarean delivery: understanding and satisfaction with mode of delivery in a subsequent pregnancy in patients participating in a formal vaginal birth after cesarean counseling program. American Journal of Perinatology 22, 217-221.

Defranco E.A., Rampersad R., Atkins K.L., Odibo A.O., Stevens E.J., Peipert J.F., Stamilio D.M. \& Macones G.A. (2007) Do vaginal birth after cesarean outcomes differ based on hospital setting? American Journal of Obstetrics \& Gynecology 197, 400.

Dunsmoor-Su R., Sammel M., Stevens E., Peipert J.L. \& Macones G. (2003) Impact of sociodemographic and hospital factors on attempts at vaginal birth after cesarean delivery. Obstetrics \& Gynecology 102, 1358-1365.

Foureur M., Ryan C., Nicholl M. \& Homer C. (2010) Inconsistent Evidence: analysis of six national guidelines for vaginal birth after cesarean. Birth 37(1), 3-10.

Fraser W.M.D.M., Maunsell E.P., Hodnett E.R.N.P. \& Moutquin J.-M.M.D.M. (1997) Randomized controlled trial of a prenatal 
vaginal birth after cesarean section education and support program. American Journal of Obstetrics \& Gynecology 176, 419-425.

Goldman G., Pineault R., Potvin L., Blais R. \& Bilodeau H. (1993) Factors influencing the practice of vaginal birth after cesarean section. American Journal of Public Health 83, 1104-1108.

Guise J.M., Mcdonagh M.S., Hashima J., Kraemer D.F., Eden K.B., Berlin M., Nygren P., Osterweil P., Krages K.P. \& Helfand M. (2003) Vaginal birth after cesarean (VBAC). Evidence Report: Technology Assessment (Summary) 71, 1-8.

Hanley M.L., Smulian J.C., Lake M.F., Mclean D.A. \& Vintzileos A.M. (1996) Analysis of repeat cesarean delivery indications: implications of heterogeneity. American Journal of Obstetrics \& Gynecology 175, 883-888.

Higgins J.P.T. \& Green S. (eds.) (2009) Cochrane Handbook for Systematic Reviews of Interventions, version 5.0.2. The Cochrane Collaboration. Retrieved from http://www.cochrane-handbook. org on 28 February 2011.

Hopkins K. (2000) Are Brazilian women really choosing caesarean section? Social Science and Medicine 51, 725-740.

Iglesias S., Burn R. \& Saunders L.D. (1991) Reducing the cesarean section rate in a rural community hospital. CMAJ: Canadian Medical Association Journal 145, 1459-1464.

Kerr-Wilson R. (2001) Caesarean section on demand. Current Obstetrics and Gynaecology 11, 126-128.

Kosecoff J., Kanouse D.E., Rogers W.H., Mccloskey L., Winslow C.M. \& Brook R.H. (1987) Effects of the National Institutes of Health Consensus Development Program on physician practice. JAMA 258, 2708-2713.

Lagrew D.C. Jr. \& Adashek J.A. (1998) Lowering the cesarean section rate in a private hospital: comparison of individual physicians' rates, risk factors, and outcomes. American Journal of Obstetrics \& Gynecology 178, 1207-1214.

Landon M., Hauth J., Leveno K., Spong C., Leindecker S., Varner M., Moawad A., Caritis S., Harper M., Wapner R., Sorokin Y., Miodovik M., Carpenter M., Peaceman A., O’sullivan M., Sibai B., Langer O., Thorp J., Ramin S., Mercer B. \& Gabbe S. (2004) Maternal and perinatal outcomes associated with a trial of labor after prior cesarean delivery. New England Journal of Medicine 351, 2581-2589.

Laws P. \& Hilder L. (2008) Australia's Mothers and Babies, 2006. AIHW National Perinatal Statistics Unit, Sydney.

Lin H. \& Xirasagar S. (2005) Maternal age and the likelihood of a maternal request for caesarean delivery: a 5 year population based study. American Journal of Obstetrics \& Gynecology 194, 848-855.

Lobel M. \& Deluca R. (2007) Psychological sequelae of caesarean delivery: review and analysis of their causes and implications. Social Science and Medicine 64, 2272-2284.

Lomas J., Anderson G.M., Domnick-Pierre K., Vayda E., Enkin M.W. \& Hannah W.J. (1989) Do practice guidelines guide practice? The effect of a consensus statement on the practice of physicians New England Journal of Medicine 321, 1306-1311.

Lomas J., Enkin M., Anderson G.M., Hannah W.J., Vayda E. \& Singer J. (1991) Opinion leaders vs audit and feedback to implement practice guidelines. Delivery after previous cesarean section. JAMA 265, 2202-2207.

Lumbiganon P., Laopaiboon M., Gülmezoglu A.M., Souza J.P., Taneepanichskul S., Ruyan P., Attygalle D.E., Shrestha N., Mori
R., Hinh N.D., Bang H.T., Rathavy T., Chuyun K., Cheang K., Festin M., Udomprasertgul V., Germar M.J., Yanqiu G., Roy M., Carroli G., Ba-Thike K., Filatova E. \& Villar J. (2010) Method of delivery and pregnancy outcomes in Asia: the WHO global survey on maternal and perinatal health 2007-08. Lancet 375, 490-499.

Macdorman M.F. \& Singh G.K. (1998) Midwifery care, social and medical risk factors and birth outcomes. Journal of Epidemiology and Community Health 52, 310-317.

Mccourt C., Weaver J., Statham H., Beake S., Gamble J. \& Creedy D. (2007) Elective cesarean section and decision making: a critical review of the literature. Birth 34, 65-79.

Misra A. (2008) Impact of the HealthChoice program on cesarean section and vaginal birth after C-section deliveries: a retrospective analysis. Maternal \& Child Health Journal 12, 266-274.

Montgomery A.A., Emmett C.L., Fahey T., Jones C., Ricketts I., Patel R.R., Peters T.J., Murphy D.J. \& Di A.S.G. (2007) Two decision aids for mode of delivery among women with previous caesarean section: randomised controlled trial. BMJ 334, 1305.

Morrison J.J., Rennie J.M. \& Milton P.J. (1995) Neonatal respiratory morbidity and mode of delivery at term: influence of timing of elective caesarean section. British Journal of Obstetrics and Gynaecology 102, 101-106.

Myers S. \& Gleicher N. (1988) A successful program to lower cesarean section rates. New England Journal of Medicine 319, 1511-1516.

Myers S.A. \& Gleicher N. (1993) The Mount Sinai cesarean section reduction program: an update after 6 years. Social Science of Medicine 37, 1219-1222.

Naiden J. \& Deshpande P. (2001) Using active management of labor and vaginal birth after previous cesarean delivery to lower cesarean delivery rates: a 10-year experience. American Journal of Obstetrics \& Gynecology 184, 1535-1541. discussion 1541-1543.

Paterson C.M. \& Saunders N.J. (1991) Mode of delivery after one caesarean section: audit of current practice in a health region. $B M J$ 303, 818-821.

Public Health Resource Unit (2007) Critical Appraisal Skills Programme. Retrieved from http://www.phru.nhs.uk/pages/PHD/ CASP.htm on 4 November 2009.

Reker D.M., Hamilton B.B., Duncan P.W., Yeh S.-C.J. \& Rosen A. (2001) Stroke: who's counting what? Journal of Rehabilitation Research and Development 38(2), 281-289.

Richardson W.S., Wilson M.C., Nishikawa J. \& Hayward R.S.A. (1995) The well-built clinical question: a key to evidence-based decisions. ACP Journal Club 123, A-12-A-13.

Richter R., Bergmann R.L. \& Dudenhausen J.W. (2007) Previous caesarean or vaginal delivery: which mode is a greater risk of perinatal death at the second delivery? European Journal of Obstetrics, Gynecology, \& Reproductive Biology 132, 51-57.

Roberts C.L., Tracy S. \& Peat B. (2000) Rates for obstetric intervention among private and public patients in Australia: population based descriptive study. BMJ 321, 137-141.

Roberts R.G., Deutchman M., King V.J., Fryer G.E. \& Miyoshi T.J. (2007) Changing policies on vaginal birth after cesarean: impact on access. Birth 34, 316-322.

Robson S.J., Laws P. \& Sullivan E.A. (2009) Adverse outcomes of labour in public and private hospitals in Australia: a populationbased descriptive study. Medical Journal of Australia 190, 474-477. 
Russillo B., Sewitch M.J., Cardinal L. \& Brassard N. (2008) Comparing rates of trial of labour attempts, VBAC success, and fetal and maternal complications among family physicians and obstetricians. Journal of Obstetrics \& Gynaecology Canada: JOGC 30, 123-128.

Sanchez-Ramos L., Kaunitz A.M., Peterson H.B., Martinez-Schnell B. \& Thompson R.J. (1990) Reducing cesarean sections at a teaching hospital. American Journal of Obstetrics \& Gynecology 163, 1081-1087. discussion 1087-1088.

Sanchez-Ramos L., Gaudier F.L. \& Kaunitz A.M. (2000) Cervical ripening and labour induction after previous cesarean delivery. Clinical Obstetrics and Gynecology 43, 513-523.

Santerre R.E. (1996) The effect of the ACOG guideline on vaginal births after cesarean. Medical Care Research \& Review 53, 315329.

Shorten A., Shorten B., Keogh J., West S. \& Morris J. (2005) Making choices for childbirth: a randomized controlled trial of a decisionaid for informed birth after cesarean. Birth 32, 252-261.

Smith G., Pell J., Pasupathy D. \& Dobbie R. (2004) Factors predisposing to perinatal death related to uterine rupture during attempted vaginal birth after caesarean section: retrospective cohort study. BMJ 329, 375-377.

Stafford R.S. (1990) Cesarean section use and source of payment: an analysis of California hospital discharge abstracts. American Journal of Public Health 80, 313-315.

Stafford R.S. (1991) The impact of nonclinical factors on repeat cesarean section. JAMA 265, 59-63.

Studnicki J., Remmel R., Campbell R. \& Werner D.C. (1997) The impact of legislatively imposed practice guidelines on cesarean section rates: the Florida experience. American Journal of Medical Quality 12, 62-68.

Thomas J., Paranjothy M. \& Royal College of Obstetricians and Gynaecologists Clinical Effectiveness Support Unit (2001) National Sentinel Caesarean Section Audit Report. Royal College of Obstetricians and Gynaecologists, London.

Traynor J.D. \& Peaceman A.M. (1998) Maternal hospital charges associated with trial of labor versus elective repeat cesarean section. Birth 25, 81-84.

Villar J., Valladres E., Wojdyla D., Zavaleta N., Guillermo C. \& Velazco A. (2006) Caesarean delivery rates and pregnancy outcomes: the 2005 WHO global survey on maternal and perinatal health in Latin America. Lancet 367, 1819-1829.

Villar J., Carroli G., Zavaleta N., Donner A., Wojdyla D., Faundes A., Velazco A., Bataglia V., Langer A., Narváez A., Valladares E., Shah A., Campodónico L., Romero M., Reynoso S., de Pádua K.S., Giordano D., Kublickas M. \& Acosta A. (2007) Maternal and neonatal individual risks and benefits associated with caesarean delivery: multicentre prospective study. British Medical Journal 335(7628), 1025-1035.

Wagner C.L. \& Metts A.K. (1999) Rates of successful vaginal delivery after cesarean for patients with private versus public insurance. Journal of Perinatology 19, 14-18.

Weaver J., Statham H. \& Richards M. (2007) Are there "unnecessary" cesarean sections? Perceptions of women and obstetricians about cesarean sections for nonclinical indications. Birth 34, 32-41.

Zweifler J., Garza A., Hughes S., Stanich M.A., Hierholzer A. \& Lau M. (2006) Vaginal birth after cesarean in California: before and after a change in guidelines. Annals of Family Medicine 4, 228-234.

The Journal of Advanced Nursing (JAN) is an international, peer-reviewed, scientific journal. JAN contributes to the advancement of evidence-based nursing, midwifery and health care by disseminating high quality research and scholarship of contemporary relevance and with potential to advance knowledge for practice, education, management or policy. JAN publishes research reviews, original research reports and methodological and theoretical papers.

For further information, please visit JAN on the Wiley Online Library website: www.wileyonlinelibrary.com/journal/jan

$\underline{\text { Reasons to publish your work in } J A N \text { : }}$

- High-impact forum: the world's most cited nursing journal and with an Impact Factor of 1.518 - ranked 9 th of 70 in the 2010

Thomson Reuters Journal Citation Report (Social Science - Nursing). JAN has been in the top ten every year for a decade.

- Most read nursing journal in the world: over 3 million articles downloaded online per year and accessible in over 7,000 libraries worldwide (including over 4,000 in developing countries with free or low cost access).

- Fast and easy online submission: online submission at http://mc.manuscriptcentral.com/jan.

- Positive publishing experience: rapid double-blind peer review with constructive feedback.

- Early View: rapid online publication (with doi for referencing) for accepted articles in final form, and fully citable.

- Faster print publication than most competitor journals: as quickly as four months after acceptance, rarely longer than seven months.

- Online Open: the option to pay to make your article freely and openly accessible to non-subscribers upon publication on Wiley Online Library, as well as the option to deposit the article in your own or your funding agency's preferred archive (e.g. PubMed). 


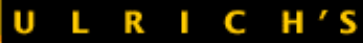
Periodicals Directory" The global source for periodicals information since-1932
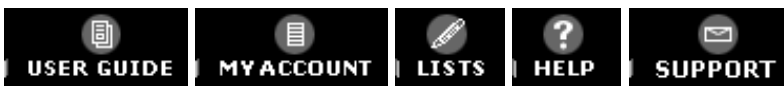

$x$

LOGOUT

\section{J ournal of Advanced Nursing}

\section{$\checkmark$ BACK TO RESULTS}

SEARCH MY LI BRARY'S CATALOG: ISSN Search | Title Search

\begin{tabular}{|c|c|c|c|c|c|}
\hline $\begin{array}{c}\text { Basic } \\
\text { Description }\end{array}$ & \multicolumn{2}{|c|}{$\begin{array}{l}\text { Other Editions/ } \\
\text { Formats }\end{array}$} & {$\left[\begin{array}{c}\text { Abstracting/ } \\
\text { Indexing \& Article } \\
\text { Access }\end{array}\right.$} & $\begin{array}{l}\text { Publisher \& } \\
\text { Ordering } \\
\text { Information }\end{array}$ & $\begin{array}{l}\text { Advertising, Rights, } \\
\text { Demographics }\end{array}$ \\
\hline \multicolumn{6}{|c|}{$J C R^{*} W e b \quad 9 S \cdot F \cdot X$} \\
\hline \multicolumn{6}{|c|}{ Click highlighted text for a new search on that item. } \\
\hline \multicolumn{2}{|c|}{ Table of Contents: } & \multicolumn{3}{|c|}{ Click here to view } & \\
\hline \multicolumn{2}{|l|}{ ISSN: } & \multicolumn{3}{|c|}{$0309-2402$} & \\
\hline \multicolumn{2}{|l|}{ Title: } & \multicolumn{3}{|c|}{ J ournal of Advanced Nursing } & $\nabla$ Additional Title Information \\
\hline \multicolumn{2}{|c|}{ Publishing Body: } & \multicolumn{3}{|c|}{ Wiley-Blackwell Publishing Ltd. } & \\
\hline \multicolumn{2}{|l|}{ Country: } & \multicolumn{3}{|c|}{ United Kingdom } & \\
\hline \multicolumn{2}{|l|}{ Status: } & \multicolumn{3}{|c|}{ Active } & \\
\hline \multicolumn{2}{|l|}{ Start Year: } & \multicolumn{3}{|c|}{1976} & \\
\hline \multicolumn{2}{|l|}{ Frequency: } & \multicolumn{3}{|c|}{ Monthly } & \\
\hline \multicolumn{2}{|c|}{ Document Type: } & \multicolumn{3}{|c|}{ J ournal; Academic/Scholarly } & \\
\hline \multicolumn{2}{|l|}{ Refereed: } & \multicolumn{3}{|l|}{ Yes } & \\
\hline \multicolumn{2}{|c|}{ Abstracted/ I ndexed: } & \multicolumn{3}{|l|}{ Yes } & \\
\hline \multicolumn{2}{|l|}{ Media: } & \multicolumn{3}{|c|}{ Print } & \\
\hline \multicolumn{2}{|c|}{$\begin{array}{l}\text { Alternate Edition } \\
\text { ISSN: }\end{array}$} & \multicolumn{3}{|c|}{$\underline{1365-2648}$} & \\
\hline \multicolumn{2}{|c|}{ RSS Availability: } & \multicolumn{3}{|c|}{ Click here to view } & \\
\hline \multicolumn{2}{|l|}{ Language: } & Text & in English & & \\
\hline Price: & & $\begin{array}{l}\text { GBP } \\
\text { EUR } \\
\text { USD } \\
\text { USD } \\
\text { GBP } \\
\text { instit } \\
\text { EUR } \\
\text { (Prin } \\
\text { USD } \\
\text { instit } \\
\text { USD } \\
\text { (Prin } \\
\text { (effe }\end{array}$ & $\begin{array}{l}\text { 1,333 subscriptio } \\
\text { 1,693 subscriptio } \\
\text { 2,466 subscriptic } \\
\text { 2,877 subscriptic } \\
\text { 1,467 combined } \\
\text { utions (Print \& O } \\
\text { 1,863 combined } \\
\text { \& Online Eds.) } \\
\text { 2,713 combined } \\
\text { utions (Print \& O } \\
\text { 3,165 combined } \\
\text { \& Online Eds.) } \\
\text { tive } 2010 \text { ) }\end{array}$ & $\begin{array}{l}\text { per year in } \\
\text { per year in } \\
\text { per year in } \\
\text { per year els } \\
\text { bscription } p \\
\text { ne Eds.) } \\
\text { bscription } p \\
\text { bscription } p \\
\text { ne Eds.) } \\
\text { bscription }\end{array}$ & $\begin{array}{l}\text { ited Kingdom to institutions } \\
\text { urope to institutions } \\
\text { e Americas to institutions } \\
\text { where to institutions } \\
\text { year in United Kingdom to } \\
\text { year in Europe to institutions } \\
\text { year in the Americas to } \\
\text { year elsewhere to institutions }\end{array}$ \\
\hline Subject: & & MED & CAL SCIENCES - & URSES AND & IURSING \\
\hline Dewey \#: & & 610. & & & \\
\hline LC\#: & & RT1 & & & \\
\hline Special Fea & res: & Inclu & des Advertising, & bliographies & llustrations, Book Reviews \\
\hline Article Ind & & Inde & & & \\
\hline Editor(s): & & Aliso & רierney (Editor & -Chief) & \\
\hline E-Mail: & & jan@ & oxon. blackwellp & ishing.com & \\
\hline URL: & & $\underline{\text { http: }}$ & //www.journalof & vancednurs & y.com/ \\
\hline Descriptior & & $\begin{array}{l}\text { Pro } \\
\text { par }\end{array}$ & tes diversity & $\begin{array}{l}\text { search ano } \\
\text { e context. }\end{array}$ & colarship in terms of culture, \\
\hline
\end{tabular}

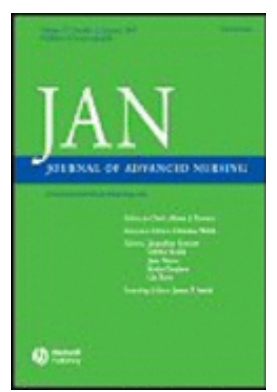

\section{ADDI TI ONAL TITLE I NFORMATI ON}

Alternate Title: Medline Abbreviated title: J Adv Nurs; Abbreviated title: J A N

A Back to Top Add this item to: (select a list) $\quad+$ ADD

\section{Request this title:}

I'd like to request this title.

\section{Corrections:}

Submit corrections to Ulrich's about this title. 